\title{
Letter to Editor: The Epidemiological Status of Carbon Monoxide Poisoning in East Azerbaijan Province (Iran) in 2016-2018
}

\author{
Farzad Rahmani $^{1^{*}}$, Ali Ostadi ${ }^{1}$, Sepideh Daneshvar
}

1.Emergency Medicine Department, Sina Medical Research and Training Hospital, Tabriz University of Medical Sciences, Tabriz, Iran.

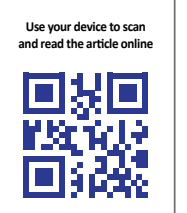

Citation: Rahmani F, Ostadi A, Daneshvar S. The Epidemiological Status of Carbon Monoxide Poisoning in East Azerbaijan Province (Iran) in 2016-2018. International Journal of Medical Toxicology and Forensic Medicine. 2021; 11(1):26926. https:// doi.org/10.32598/ijmtfm.v11i.26926

https://doi.org/10.32598/ijmtfm.v11i.26926

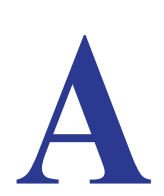

\section{Dear Editor}

cute poisoning is considered a major public health problem and one of the most common causes of referral to the emergency wards worldwide $[1,2]$. Carbon monoxide (CO) is one of the most dangerous environmental pollutants [3].

$\mathrm{CO}$ is a light, colorless, odorless, tasteless, and nonstimulant gas produced from incomplete combustion of fuels, tobacco, and other carbon-containing materials. The affinity of CO for hemoglobin is 240 times that of oxygen; therefore, even inhalation of a small volume of CO can lead to severe tissue hypoxia [3]. The heart and brain have a high metabolism rate and are more susceptible to $\mathrm{CO}$-induced poisoning damage [4-6].

This descriptive cross-sectional study was conducted at Prehospital Emergency and Disaster Management Center of Tabriz University of Medical Sciences and the information of the patients transferred to the hospital and diagnosed with CO poisoning was collected from 20162018. Data, including age, gender, time of the accident, location and cause of the accident, vital signs, and outcome of the patient were collected at the incident scene. Inclusion criteria included the patients who had been diagnosed with $\mathrm{CO}$ poisoning and referring to the treat- ment centers during the mentioned period. Exclusion criteria included incomplete medical records. This study was approved by the Ethics Committee of Tabriz University of Medical Sciences (Ethics code: IR.TBZMED. REC.1397.652) on July 25, 2018. Data were analyzed using SPSS 17 software. The Kolmogorov-Smirnov test was used to investigate the normal distribution of the data. Descriptive data were analyzed using descriptive statistics.

In the present study, a total of 2344 medical records were evaluated, of which 53 cases were excluded due to incomplete information. Finally, the medical records of 2291 patients were evaluated. The mean age of the patients was $30.62 \pm 17.32$ years (ranging from 1-93 years). Regarding gender, 1010 patients (44.1\%) were male and the rest were women. In terms of the accident site, 1963 patients $(85.7 \%), 49$ patients $(2.1 \%)$, and 236 patients $(10.3 \%)$ were injured at home, work, and in the backpacking tents, respectively and the rest were injured in the wedding hall. Concerning the cause of the accident, 1309 patients $(57.1 \%), 840$ patients $(36.7 \%)$, and 132 patients $(5.8 \%)$ were injured as a result of being exposed to the fireplace, wall-mounted water heater, and picnic gas stove, respectively and the rest were injured due to the exposure to the fireplace. Moreover, 484 patients (21.1\%), 79 patients $(3.4 \%), 673$ patients $(29.4 \%)$, and 1053 patients $(46 \%)$ were injured in spring, summer, 
fall, and winter, respectively. The highest and lowest number of poisoned patients were found in January (431 patients, 18.8\%) and August (24 patients, 1\%), respectively. Among the patients examined, 66 patients $(2.9 \%)$ died at the incident scene. The mean age at death was $33.84 \pm 15.77$ years.

The average vital symptoms of the survived patients included a heart rate of $93.24 \pm 23.15 \mathrm{bpm}$, mean arterial pressure of $81.18 \pm 61.67 \mathrm{mmHg}$, and arterial oxygen saturation of $93.39 \pm 16.22 \%$.

Awareness of the poisoning pattern in a specific region plays an important role in identifying risk factors and early diagnosis [7]. The majority of the study population included the women who were poisoned at home and as a result of exposure to the gas heater, and poisoning occurred mostly in January. The lowest poisoning incidence was recorded in August.

Sircar et al. showed a death rate of 1.48 deaths per million population due to $\mathrm{CO}$ poisoning, of which $54 \%$ of deaths had been occurred at home [8]. Chan et al. reported that the highest rate of $\mathrm{CO}$ poisoning incidence was observed in winter the mean age of patients was 36 years [9].

The following measures can be effective in reducing the incidence of $\mathrm{CO}$ poisoning: implementing various preventive education programs for families at home, school, workplace, public media, and social networks, especially before the start of the cold seasons on how to set up standard heating equipment, checking the chimney pipes, and ensuring the appropriate site for installation of a wall-mounted water heater, along with training the first aid principles for CO-poisoned patients.

\section{Ethical Considerations}

\section{Compliance with ethical guidelines}

This study was approved by the Ethics Committee of Tabriz University of Medical Sciences (Ethics code: IR.TBZMED. REC.1397.652) on July 25, 2018.

\section{Funding}

This research did not receive any grant from funding agencies in the public, commercial, or non-profit sectors.

\section{Author's contributions}

All authors equally contributed to preparing this article.

\section{Conflict of interest}

The authors declared no conflict of interest.

\section{References}

[1] Camilleri R. An overview of suspected and acute poisoning in Mater Dei Hospital. Malta Med J. 2014; 26(3):21-6. https:/ / www.um.edu.mt/library/oar//handle/123456789/1658

[2] Lund C, Teige B, Drottning P, Stiksrud B, Rui TO, Lyngra $\mathrm{M}$, et al. A one-year observational study of all hospitalized and fatal acute poisonings in Oslo: Epidemiology, intention and follow-up. BMC Public Health. 2012; 12:858. [DOI:10.1186/1471-2458-12-858] [PMID] [PMCID]

[3] Wu PE, Juurlink DN. Carbon monoxide poisoning. CMAJ. 2014; 186(8):611. [DOI:10.1503/cmaj.130972] [PMID] [PMCID]

[4] Huang CC, Chung MH, Weng SF, Chien CC, Lin SJ, Lin HJ, et al. Long-term prognosis of patients with carbon monoxide poisoning: A nationwide cohort study. PloS One. 2014; 9(8):e105503. [DOI:10.1371/journal.pone.0105503] [PMID] [PMCID]

[5] Zou JF, Guo Q, Shao H, Li B, Du Y, Liu M, et al. A positive Babinski reflex predicts delayed neuropsychiatric sequelae in Chinese patients with carbon monoxide poisoning. Bio Med Res Int. 2014; 2014:814736. [DOI:10.1155/2014/814736] [PMID] [PMCID]

[6] Zou JF, Guo Q, Shao H, Li B, Du Y, Liu M, et al. Lack of pupil reflex and loss of consciousness predict 30-day neurological sequelae in patients with carbon monoxide poisoning. PloS One. 2015; 10(3):e0119126. [DOI:10.1371/journal. pone.0119126] [PMID] [PMCID]

[7] Abd-Elhaleem ZAE, Al Muqhem BA. Pattern of acute poisoning in Al Majmaah region, Saudi Arabia. Am J Clin Exp Med. 2014; 2(4):79-85. http://www.sciencepublishinggroup. $\mathrm{com} /$ journal $/$ paperinfo.aspx?journalid $=254 \&$ doi $=10.11648$ /j.ajcem.20140204.15

[8] Sircar K, Clower J, Shin MK, Bailey C, King M, Yip F. Carbon monoxide poisoning deaths in the United States, 1999 to 2012. Am j Emerg Med. 2015; 33(9):1140-5. [DOI:10.1016/j. ajem.2015.05.002] [PMID] [PMCID]

[9] Chan MY, Au TS, Leung KS, Yan WW. Acute carbon monoxide poisoning in a regional hospital in Hong Kong: Historical cohort study. Hong Kong Med J. 2016; 22(1):46-55. [DOI:10.12809/hkmj144529] 